\title{
JOURNAL.RU
}

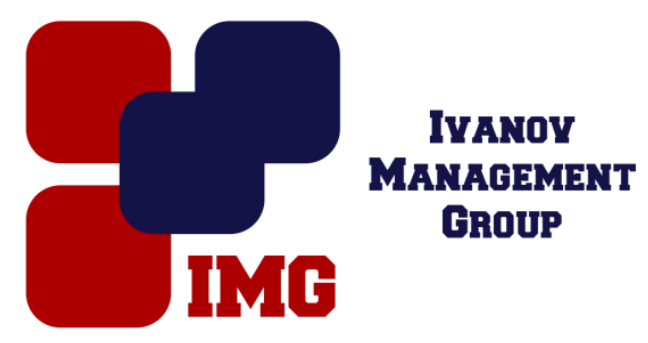

Архипов М. Е., Родионова О. В., Ситникова Л.Д. Тульский государственный педагогический университет им. Л.Н. Толстого

Тула, Россия

doi: $10.18411 / \mathrm{lj}-31-05-2017-20$

idsp 000001:1j-31-05-2017-20

\section{Информационные технологии в рамках реализации повышения квалификации и профессиональной переподготовки учителей математики в Тульской области}

\section{Аннотация}

В статье рассматриваются вопросы повышения квалификации и профессиональной переподготовки учителей математики в рамках реализации концепции математического образования в Тульской области. Анализируется программа для педагогических кадров, имеющих квалификацию учителя математики: «Актуальные проблемы теории и методики преподавания математики в условиях реализации ФГОС основного общего образования».

Ключевые слова: Федеральный государственный образовательный стандарт основного общего образования нового поколения, математическое образование, профессиональная подготовка, повышение квалификации, процесс обучения, профессиональные компетенции учителей математики.

\section{Abstract}

This article deals with the training and retraining of teachers of mathematics as part of the mathematical concept of education in the Tula region. Analyzes the program for teaching staff with qualifications of a teacher of mathematics: "Actual problems of theory and methodology of teaching mathematics in a GEF implementing basic general education."

Keywords: Federal state educational standard of basic general education of a new generation, mathematical education, training, professional development, learning, professional competence of teachers of mathematics. 
В настоящее время актуальной является проблема отсутствия учителейматематиков в малокомплектных и сельских учебных заведениях или их не достаточное количество для реализации учебного процесса. В этих случаях нередко для преподавания математики привлекаются учителя, не имеющие соответствующую квалификацию.

В помощь таким учителям подготовлена к реализации программа переподготовки: «Теория и методика преподавания математики в условиях реализации ФГОС общего образования», направленная на систематизацию математических знаний $\mathrm{c}$ целью применения современных методик и технологий в области математики для обеспечения качества учебного процесса, совершенствование профессиональных компетенций учителей математики, а также получение новых, в соответствии с профессиональным стандартом педагога и Федеральными государственными образовательными стандартами основного общего образования нового поколения.

Реализуя данную программу мы решаем следующие задачи:

- ознакомление слушателей с основными концептуальными положениями образовательных стандартов нового поколения применительно к практике преподавания математики в школе;

- актуализация интеллектуально-творческих способностей учителей математики, направленных на освоение ресурсов ФГОС, включая формирование универсальных учебных действий как педагогического средства для построения эффективной системы школьного математического образования;

- обучение слушателей специфике разработки методического обеспечения новых образовательных стандартов и усовершенствование знаний слушателей в области современных образовательных технологий и их применения к организации учебного процесса по математике в условиях введения ФГОС;

- проектирование и реализация программы развития УУД в школьном курсе математики;

- развитие предметной и методологической компетентности слушателей в вопросах преподавания математики;

- формирование умения включать в образовательный процесс по математике междисциплинарную и метапредметную проблематику. 
В процессе изучения курса рассматривается ряд теоретикометодологических и методических вопросов, касающихся определения и структуры учебной деятельности, основных психологических механизмов процесса усвоения знаний и умений, а также актуальных вопросов теории и методики преподавания математики. Практическая часть курса помогает педагогам овладеть наиболее эффективными средствами и формами достижения результатов географического образования.

Программа рассчитана на 126 часов и состоит из 7 модулей, направленных на изучение основных направлений современного образовательного процесса. Реализация содержания программы включает большую самостоятельную работу слушателей с использованием информационных технологий и дистанционного обучения, в частности ресурсов среды электронного обучения LMS Moodle, которая позволяет:

1) структурировать учебный материал по разделам и темам в соответствии с программой;

2) осуществлять входной, промежуточный и итоговый контроль усвоения знаний с помощью специализированного ресурса «Лекция» и встроенного средства создания тестов;

3) отслеживать активность слушателей;

4) анализировать результаты обучения;

5) создавать учебное портфолио каждого слушателя.

С помощью дистанционного обучения слушатели имеют возможность:

1) самостоятельно изучить лекционный материал, ознакомиться с дополнительными материалами углубленного изучения математики, систематизировать накопленный и получить новый опыт практический работы, самостоятельно выполнить задания по рассмотренным темам;

2) скорректировать начальный уровень знаний еще до начала занятий, а также познакомиться с новым материалом, попрактиковаться и повторить изученное.

Постоянному контролю знаний студентов помогает система тестирования, что освобождает преподавателя от рутинной работы, приводит к повышению интереса к занятиям у студентов. При этом происходит естественное освоение современных ИКТ и средств эффективной организации учебной деятельности, что способствует развитию информационно-коммуникационной компетентности. 
При дистанционной работе предусмотрена индивидуальная траектория вступительного тестирования, дальнейшего обучения, промежуточных и итоговых отчетностей каждого слушателя.

В курсе использованы различные формы представления учебной информации, способные влиять на уровень знаний, приобретаемых слушателями, создавать неформальные сообщества участников и разработчиков курса.
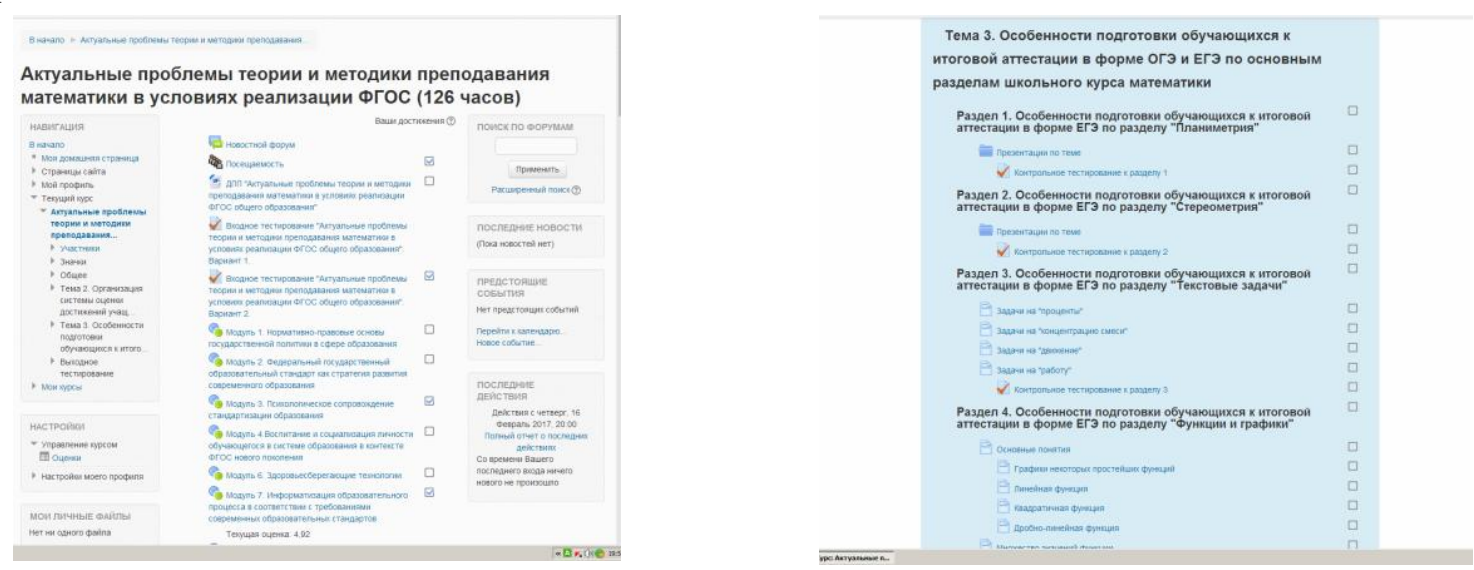

Рисунок 1. Дистанционный курс в среде LMS Moodle Модуль 6. Информатизация образовательного процесса в соответствии с требованиями современных образовательных стандартов

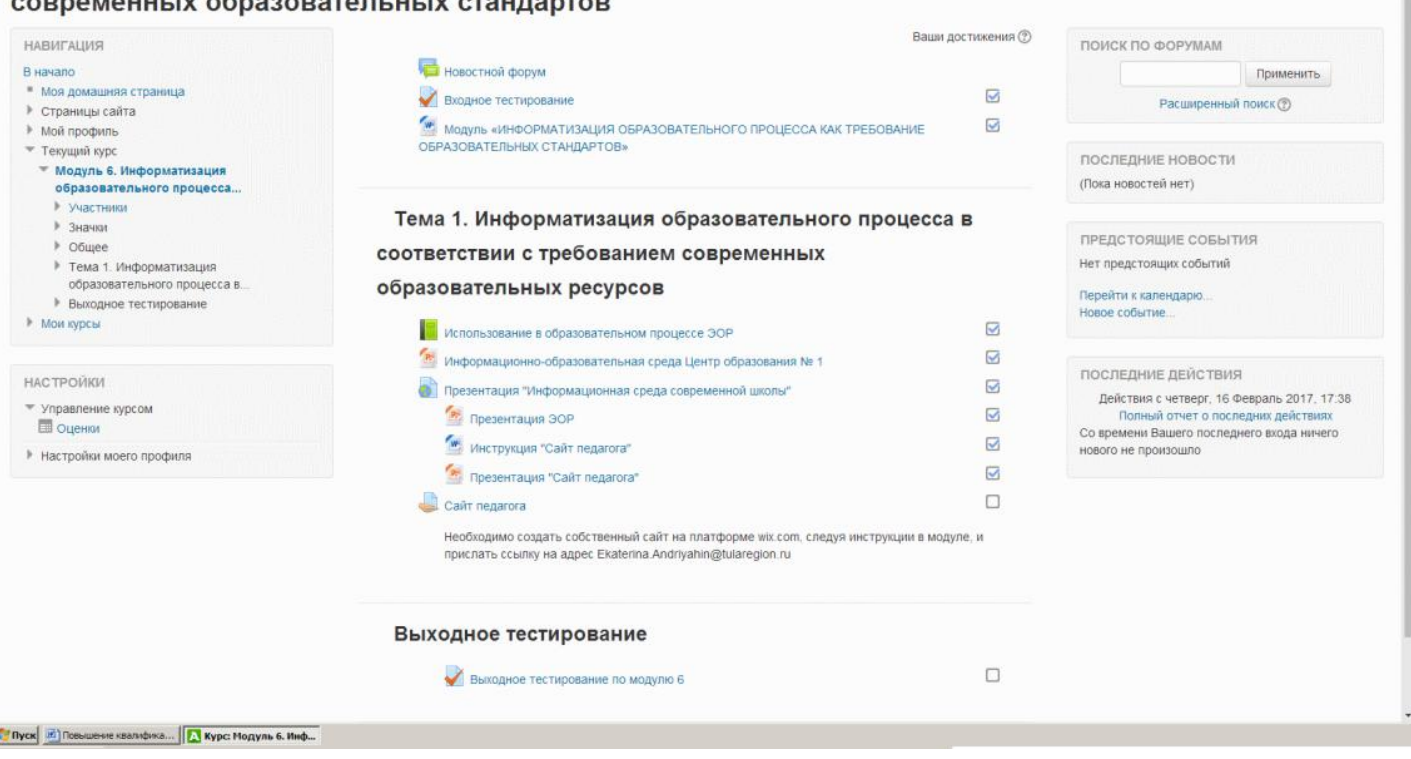

Рисунок 2. Структура модуля дистанциионного курса

Лекционный блок курса представлен в виде книг с оглавлением и возможностью нелинейного перехода по разделам, которые содержат основные понятия и теоретический материал по изучаемым темам. 
Актуальные проблемы теории и методики преподавания математики в условиях реализации ФГОС (126 часов)

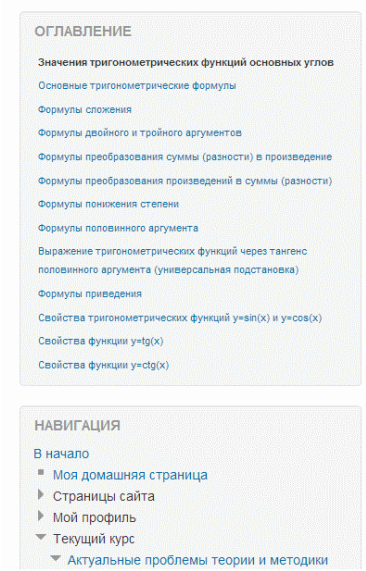

Тождественные преобразования тригонометрических выражений. Тригонометрические функции

Значения тригонометрических функций основных углов

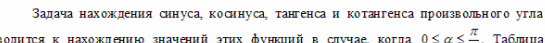

определяет основные значения $\sin \alpha, \cos \alpha, \operatorname{tg} \alpha$ и стg $\alpha$ для данн ого промежули

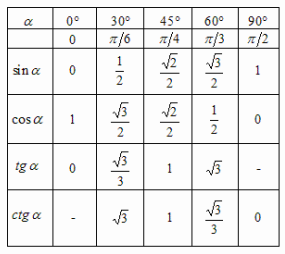

Выходное тестирование

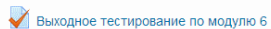

Рисунок 3. Теоретический материал дистаниионного курса

Для самостоятельной проверки понимания теоретических вопросов предлагаются тренажерные тесты с пояснениями к ответам, они позволяют отработать конкретные знания, умения, навыки, а также учитывают индивидуальный темп работы.

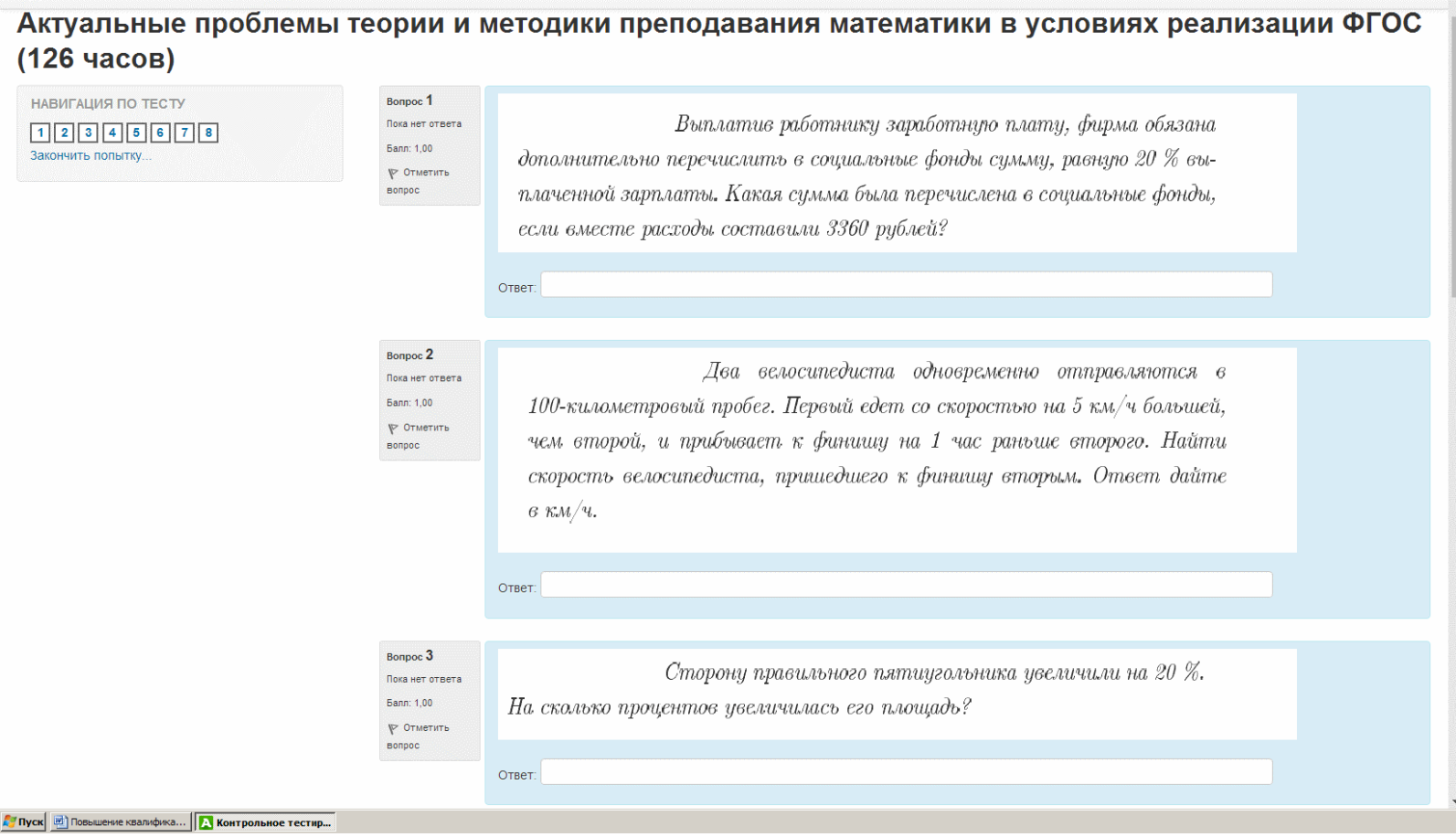

Рисунок 4. Пример теста текущего контроля дистанщионного курса

В конце обучения слушателям предлагается выходное тестирование, содержание данных тестов проверяет уровень освоения изученного материала. 
Актуальные проблемы теории и методики преподавания математики в условиях реализации ФГОС (126 часов)
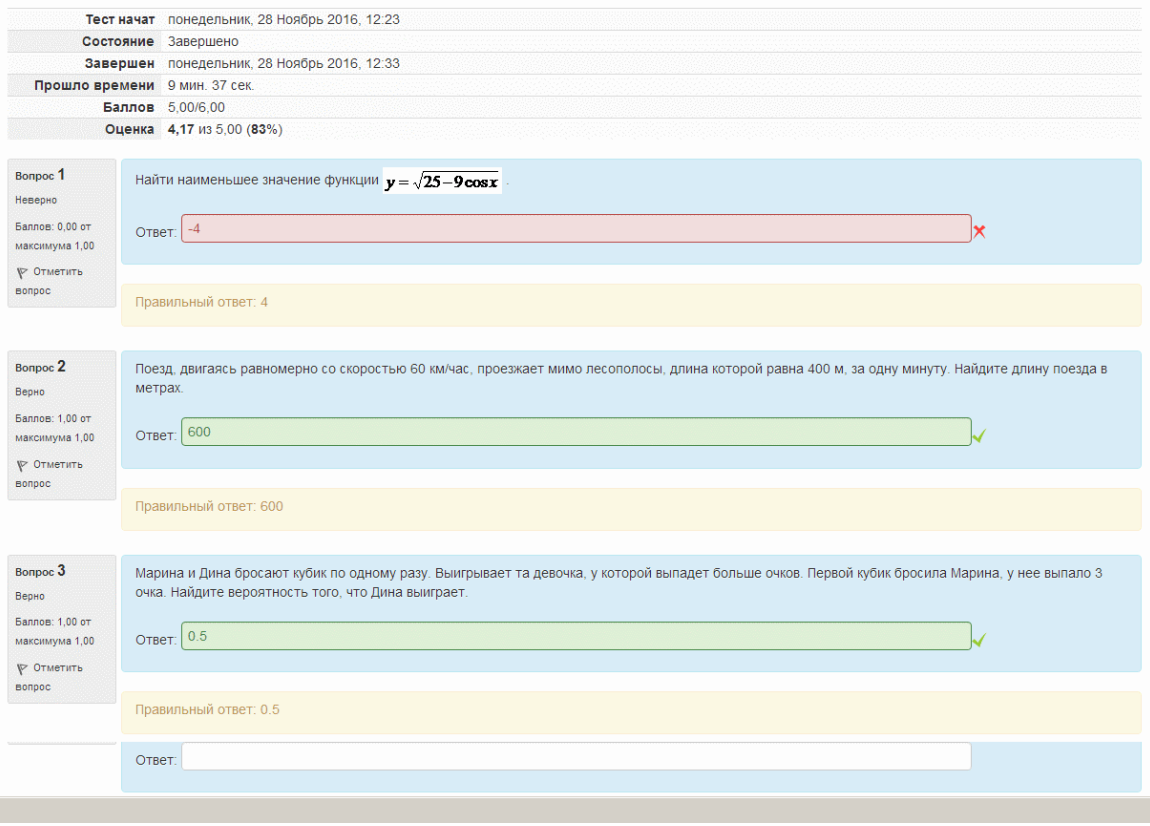

Рисунок 5. Вариант выходного теста дистанционного курса

Раздел «Профессиональная компетентность учителя математики» предполагает наличие самостоятельной творческой работы на тему «Современный урок математики» и содержит задание: разработайте конспект урока в соответствии с новыми требованиями ФГОС. (Тема урока по выбору слушателя. Примерная форма размещена в LMS Moodle.)

В разделе «Реализация требований ФГОС к результатам образования средствами школьного курса математики. Развитие УУД в курсе математики» используется комплексный вид деятельности, включающий самостоятельную творческую и информационно-поисковую работу с элементами анализа учебнометодических и научных источников. Отчетом по данному разделу являются разработанные задания, направленные на формирование основных видов УУД в курсе математики (по выбору слушателя).

Раздел «Особенности предметного содержания и методического обеспечения линий УМК по математики. Особенности подготовки обучающихся к итоговой аттестации в форме ОГЭ и ЕГЭ по основным разделам школьного курса математики» направлен на самостоятельное рассмотрение некоторых методик изучения основных разделов математики с дистанционными и очными консультациями преподавателей.

В качестве заданий предполагается решение типовых задач ЕГЭ и ОГЭ по математике, используя банк данных, размещенный в среде электронного 
обучения LMS Moodle, выполнение тестовых заданий и самостоятельная разработка тестовых и контрольных заданий на предложенных примерах.

Результаты своей деятельности слушатели могут видеть здесь же, в своем профиле в разделах «Отчет по пользователю» или «Обзорный отчет» (рис. 6 и 7)

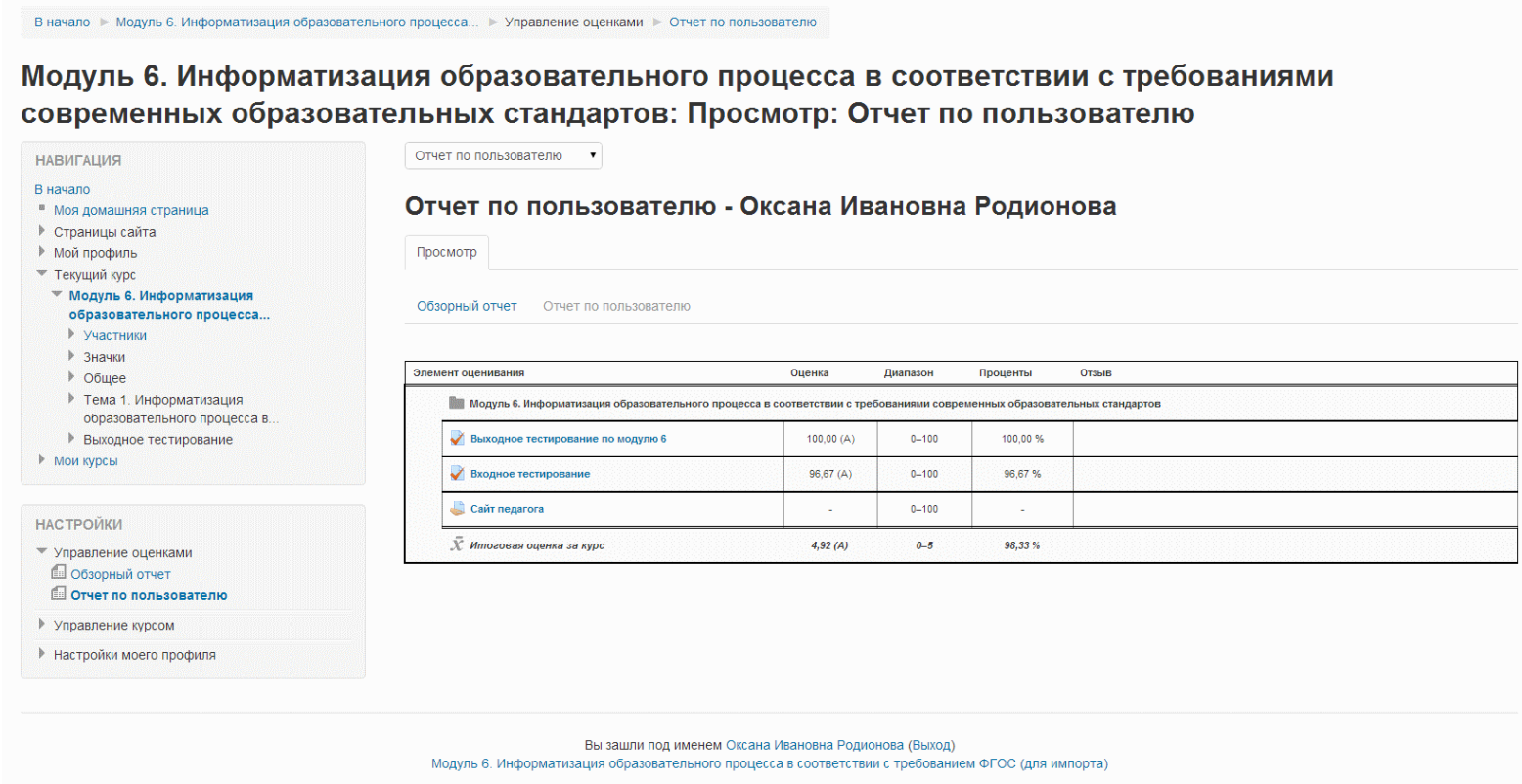

Рисунок 6. «Отчет по пользователю» дистанциионного курса

Модуль 6. Индорматизация образовательного процесса в соответствии с требованиями современных образовательных стандартов: Просмотр: Обзорный отчет
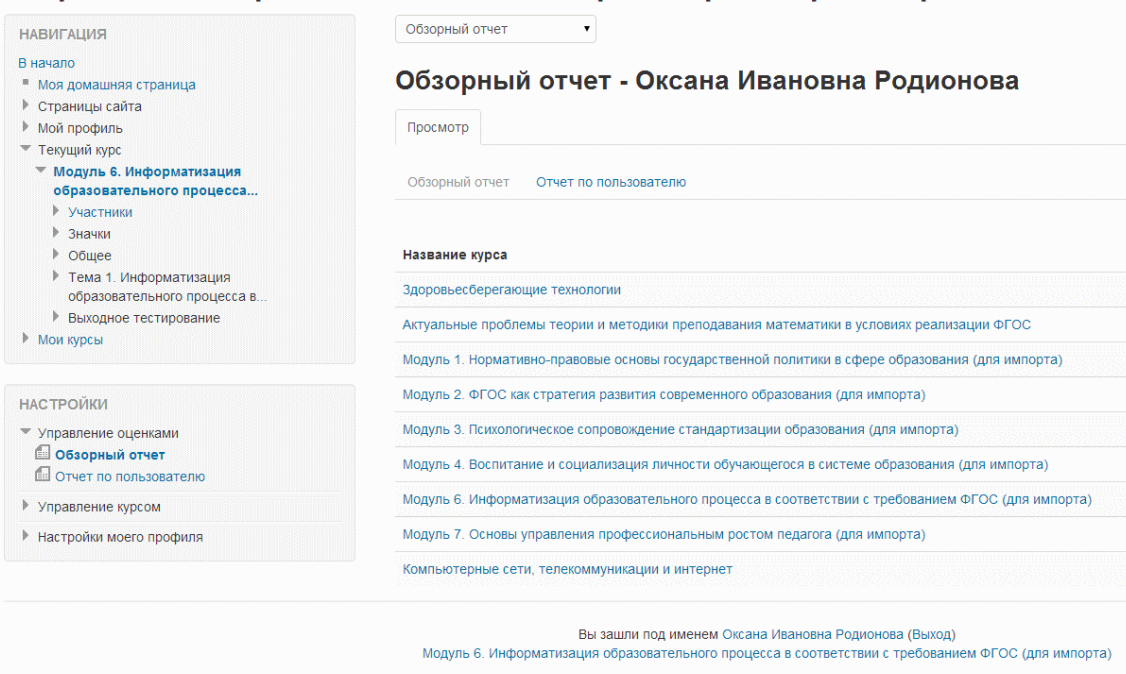

Рисунок 7. «Обзорный отчет» дистаниионного курса в среде LMS Moodle 
1. Архипов М.Е., Родионова О.В. Повышение квалификации и профессиональная переподготовка учителей математики в рамках реализации концепции математического образования в тульской области // Современное образование: актуальные вопросы, достижения и инновации: Материалы V международной научнопрактической конференции. - Пенза: МЦНС «Наука и Просвещение». - 2017. С. 152 159

2. Родионова О.В., Мусатова И.Л., Бойкова О.И., Половецкая О.С. Опыт использования среды электронного обучения LMC MOODLE Научно-методический электронный журнал Концепт. 2015. № 10. С. 